\title{
In search of the ideal valve replacement device
}

\author{
John E. Mayer, Jr, MD
}

From The Children's Hospital, Boston, Mass.

Received for publication March 7, 2001; accepted for publication March 20, 2001.

Address for reprints: John E. Mayer, MD, The Children's Hospital Boston, 300 Longwood Ave, Boston, MA 02115 (E-mail: john.meyer@tch.harvard.edu).

J Thorac Cardiovasc Surg 2003;125:S14-5 Originally published in J Thorac Cardiovasc Surg 2001;122:8-9.

Copyright $(92003$ by The American Association for Thoracic Surgery

$0022-5223 / 2003 \$ 30.00+0$

doi: $10.1067 / \mathrm{mtc} .2003 .211$

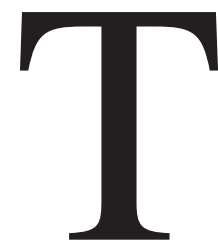

he search for an ideal cardiac valve replacement began in the earliest days of cardiac surgery, and the commandments describing the essential characteristics of an ideal valve replacement device were outlined by Dwight Harken ${ }^{1}$ in the 1950s. These characteristics include durability, absence of thrombogenicity, resistance to the ability to provide normal hemodynamics, absence of damage to blood elements, and technical practicality of insertion in a physiologic position in the circulation. Additional desirable characteristics include resistance to infection and lack of immunogenicity. If valves are to be used in children, the capacity for growth must be included as well. Many prosthetic and bioprosthetic valves provide good hemodynamic performance with low gradients and insignificant regurgitation. However, no prosthetic valve will be able to meet the nonthrombogenicity criterion because a nonthrombogenic, blood-compatible surface has not yet been developed. All prosthetic and bioprosthetic valves remain more susceptible to infection than native valves, a characteristic that is related to the microfilms that cover most implanted prosthetic surfaces. Native valves are living structures that continuously remodel and repair their structural proteins (collagen, elastin, and glycosamino glycans), and because no current bioprosthetic valves contain living cells, these valves predictably have limited durability. Debate continues over the value of living cells in a homograft valve, but there is no evidence that homograft valves have living interstitial cells that can carry out the remodeling and repair functions of a normal valve. The work in the accompanying article demonstrates that both valve endothelial and interstitial cells are capable of evoking an immune response in vitro and support the concept that immune factors may prove to be important to long-term homograft function. Because no currently available prosthetic, bioprosthetic, or homograft valve fulfills all of these requirements, the search continues.

There is now increasing interest in trying to find ways to create a truly living valve structure that will have a nonthrombogenic endothelial surface and a living interstitium with repair and remodeling capabilities. Several groups, including our own, are pursuing a tissue-engineering approach in which tissue constructs are created from individual cellular components by seeding cells onto biodegradable scaffolds $^{2}$ or a matrix of decellularized allograft tissue. ${ }^{3}$ There have been some early favorable results with these approaches in experimental animals, ${ }^{2,3}$ but many questions remain, including the following. What is the preferred scaffolding material on which to have the cells organize, a biodegradable polymer or a decellularized native valve matrix? What type of cells should be used to populate the matrix, and must they be autologous? Can progenitor or stem cells circulating in the bloodstream repopulate an acellular or decellularized matrix, or must the cells be cultured onto scaffolds in vitro? Can these tissue-engineered structures remain viable, sustain the wear and tear of the normal circulation over a lifetime, and grow in pediatric patients? Will human cells cultured on scaffolds or a decellularized matrix behave in the same way that cells from other mammalian species behave? The answers to these and other questions are actively being addressed and will help to determine whether the tissue-engineering approach will prove clinically applicable.

However, as we pursue the goal of an ideal valve replacement, the stimulus of these attempts will also be likely to lead to a better understanding of the normal architecture and biology of cardiac valves and of the abnormal developmental and pathologic processes that affect them. The work in the accompanying article is an 
important example of this stimulus and effect. There is clearly a process at work in which pursuit of a solution to a clinical need leads to renewed interest in understanding more basic aspects of normal and abnormal biology. This effect is similar to the ways in which the development of the surgical capability to address congenital heart disease in the 1940s and 1950s spurred renewed interest in the pathologic anatomy of congenital heart disease. As a surgical investigator in this era of the genetic revolution, I hope that we will always remember the importance of a 2-way flow of information and intellectual stimulation between basic science and clinical science. Neither can or should proceed independently of the influence of the other.

\section{References}

1. Harken DE. Heart valves: ten commandments and still counting. Ann Thorac Surg. 1989;48:S18-9.

2. Hoerstrup SP, Sodian R, Daebritz S, Wang J, Bacha EA, Martin DP, et al. Functional living trileaflet heart valves grown in vitro. Circulation. 2000;102(Suppl):III-44-9.

3. Steinhoff G, Stock U, Karim N, Mertsching H, Timke A, Meliss RR, et al. Tissue engineering of pulmonary heart valves on allograft acellular matrix conduits: in vivo restoration of valve tissue. Circulation. 2000;102(Suppl):III-50-55. 